\title{
Rhombohedral-structured LiVO 2 Prepared by a Novel Two- Step Method and Its Electrochemical Properties
}

\author{
Xiaohui Li, Zhi Su*, Huanling Tian, Yanhui Zhang \\ College of Chemistry and Chemical Engineering, Xinjiang Normal University, Urumqi, 830054, \\ Xinjiang, China \\ *E-mail: suzhixj@sina.com
}

doi: $10.20964 / 2017.01 .66$

Received: 23 October 2016 / Accepted: 4 December 2016 / Published: 12 December 2016

Layered $\mathrm{LiVO}_{2}$ was prepared as a cathode material for lithium ion batteries by a novel two-step reduction method. The structure and morphology of the material were characterized by X-ray diffraction, X-ray photoelectron spectroscopy, and transmission electron microscopy. The specific capacity of the material reached $201.7 \mathrm{mAh} \mathrm{g}^{-1}$ when charged and discharged at a rate of $0.2 \mathrm{C}$ in the voltage range of $1.0-4.5 \mathrm{~V}$. The retention ratio of discharge capacity was $65 \%$ after 30 cycles. The charge-transfer resistance calculated by fitting the experimental electrochemical impedance data to the equivalent circuit model was $81.65 \Omega$. From this, the lithium ion diffusion coefficient was calculated to be $2.72 \times 10^{-11} \mathrm{~cm} \mathrm{~s}^{-1}$, indicating that this material exhibits excellent ionic and electronic conductivity.

Keywords: $\mathrm{LiVO}_{2}$; two-step method ; cathode materials; electrochemical performance

\section{$\underline{\text { FULL TEXT }}$}

(C) 2017 The Authors. Published by ESG (www.electrochemsci.org). This article is an open access article distributed under the terms and conditions of the Creative Commons Attribution license (http://creativecommons.org/licenses/by/4.0/). 